\title{
The Surgical Treatment for Ischemic Heart Failure trial: A landmark study
}

\author{
Juan A. Crestanello, MD, and Richard C. Daly, MD
}

\author{
From the Department of Cardiovascular Surgery, Mayo Clinic, Rochester, Minn. \\ Disclosures: Authors have nothing to disclose with regard to commercial support. \\ Received for publication Oct 13, 2018; accepted for publication Oct 15, 2018; available ahead of print Nov 30, \\ 2018 \\ Address for reprints: Juan A. Crestanello, MD, Department of Cardiovascular Surgery, Mayo Clinic, 200 First St, \\ SW, Rochester, MN 55905 (E-mail: crestanello.juan@mayo.edu). \\ J Thorac Cardiovasc Surg 2019;157:958-9 \\ $0022-5223 / \$ 36.00$ \\ Copyright (c) 2018 by The American Association for Thoracic Surgery \\ https://doi.org/10.1016/j.jtcvs.2018.10.066
}

The Surgical Treatment for Ischemic Heart Failure (STICH) trial is a landmark study that has profoundly influenced the practice of cardiac surgery and cardiovascular medicine. ${ }^{1}$ The trial represents a monumental effort by the National Institutes of Health-National Heart, Lung, and Blood Institute; the study leadership; the participating centers; and the patients who enrolled in the trial to determine whether coronary artery bypass graft (CABG) surgery combined with optimal medical therapy (OMT) is superior to OMT alone to treat patients with left ventricle dysfunction. ${ }^{2,3}$ Michler ${ }^{4}$ presents a comprehensive and eloquent summary of the STICH trial results and their application to clinical practice. The overwhelming evidence supports the use of CABG with OMT as a revascularization strategy in patients with coronary artery disease and decreased left ventricular ejection fraction (LVEF). The combination of CABG and OMT results in improved overall survival, improved freedom from cardiovascular death, and repeat hospitalization at 10 years. ${ }^{3}$ Michler $^{4}$ also reviews the implications of the use of angina, myocardial viability, inducible ischemia, and left ventricle volume as factors to support clinical decisions for OMT alone versus combined CABG with OMT.

Since its conception, the STICH trial has been associated with significant controversies and such controversies increased significantly as the results of the trial were published because many of them were unexpected or were against long-standing clinical practice, assumptions, and understanding of pathophysiology. ${ }^{5-11}$ The lack of benefit of surgical ventricle restoration (SVR), ${ }^{5}$ the lack of survival benefit between CABG and medical therapy at 5 years, ${ }^{2}$ the lack of survival benefits of $\mathrm{CABG}$ on patients with viability ${ }^{12}$ or with symptoms of angina, ${ }^{13}$ and the improved outcomes of CABG on patients with larger ventricles and lower LVEF are some of those unexpected result. ${ }^{14}$

Although many have attributed these results to design flaws, patient selection, post hoc analysis, insufficient follow-up, and insufficient reduction in left ventricle volumes, several points can be made about them: the trial

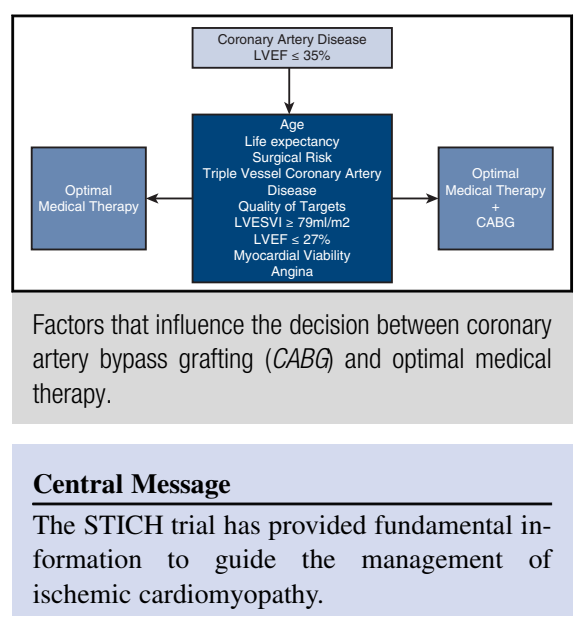

See Article page 950. results represent the best data available to this moment for the treatment of patients with coronary artery disease and left ventricle dysfunction; it is unlikely that another randomized clinical trial will be performed to further clarify them in the near future; OMT is an essential component of the treatment of patients with ischemic cardiomyopathy ${ }^{11}$; and the results of the trial are complex and cannot be summarized in short sound bites such as "CABG does not offer a survival benefit," "SVR does not help" or, "Myocardial viability and angina are not important." There are nuances to each of those statements that physicians need to consider as they make clinical decisions. For example, whereas CABG did not improve survival at the 5-year analysis, it provided substantial improvement in survival at 10 years and the benefit was even greater in the as-treated analysis. $^{2,3}$ In hypothesis 2, patients with smaller ventricles at baseline and those who achieved significant reduction in left ventricle volumes after SVR had improved survival compared with those undergoing CABG alone. ${ }^{15,16}$ Patients with viability had better survival than patients without viability, but the benefit was loss after adjustment for baseline characteristics. ${ }^{12}$ There was no interaction between myocardial viability, treatment arm (ie, CABG + OMT vs OMT alone) and survival. $^{12}$ This is perhaps among the most controversial results of the trial where the viability methodology used, the binary nature of the viability analysis, the low number of patients who underwent viability studies $(<50 \%)$, the even smaller number of patients with nonviable myocardium 


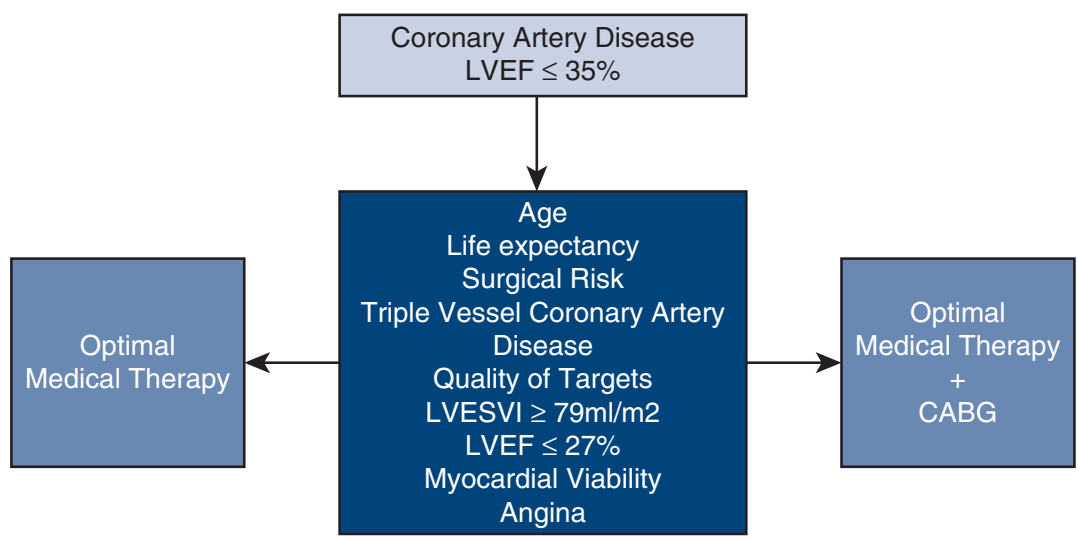

FIGURE 1. Factors that influence the decision between coronary artery bypass grafting $(C A B G)$ and optimal medical therapy versus optimal medical therapy alone. $L V E F$, Left ventricular ejection fraction; LVESVI, left ventricle end systolic volume index.

$(<10 \%)$, and the lack of specification of other ventricle characteristics such as location of nonviability and ventricle wall thickness limit the interpretation of these results. ${ }^{12,17}$ In terms of angina, CABG provided a survival benefit compared with OMT alone in both patients with and without angina at baseline when the results are analyzed as treated. ${ }^{13}$ Finally, patients with the most severe forms of ischemic cardiomyopathy (ie, larger ventricles, more extensive coronary artery disease, and lower LVEF) have improved survival with CABG + OMT. ${ }^{14}$ Age and life expectancy should be other factors to consider as CABG is contemplated - particularly for elderly patients. Although CABG surgery is associated with increased early mortality, it takes at least 2 years for the survival benefits of CABG over OMT alone to be evident. ${ }^{14}$ As expected, the benefits of CABG in reducing overall mortality, but not cardiovascular mortality, is diminished in older patients. ${ }^{18}$

The translation of clinical trial data into clinical management for an individual patient is always challenging and not a single isolated variable can be used to decide to add CABG to OMT. Considerations about age, life expectancy, surgical risk, functional status, extent of coronary artery disease, quality of targets, ventricle volume and function, viability, extension and location of viability, and angina symptoms, should be considered (Figure 1). The STICH trial has provided fundamental but imperfect evidencebased information to guide the management of disease in these challenging patients.

\section{References}

1. Velazquez EJ, Lee KL, O'Connor CM, Oh JK, Bonow RO, Pohost GM, et al. The rationale and design of the Surgical Treatment for Ischemic Heart Failure (STICH) trial. J Thorac Cardiovasc Surg. 2007;134:1540-7.

2. Velazquez EJ, Lee KL, Deja MA, Jain A, Sopko G, Marchenko A, et al. Coronary-artery bypass surgery in patients with left ventricular dysfunction. $N$ Engl J Med. 2011;364:1607-16.

3. Velazquez EJ, Lee KL, Jones RH, Al-Khalidi HR, Hill JA, Panza JA, et al. Coronary-artery bypass surgery in patients with ischemic cardiomyopathy. $N$ Engl J Med. 2016;374:1511-20.
4. Michler RE. A decade after the STICH trial: weaving firm clinical recommendations from lessons learned. J Thorac Cardiovasc Surg. 2019;157: 950-7.

5. Jones RH, Velazquez EJ, Michler RE, Sopko G, Oh JK, O’Connor CM, et al. Coronary bypass surgery with or without surgical ventricular reconstruction. $\mathrm{N} \mathrm{Engl}$ J Med. 2009;360:1705-17.

6. Balsam LB, Grossi EA. Surgical ventricular reconstruction has a role in surgical remodeling in patients with LV systolic dysfunction even post-STICH? Prog Cardiovasc Dis. 2013;55:481-6.

7. Buckberg GD, Athanasuleas CL, Wechsler AS, Beyersdorf F, Conte JV, Strobeck JE. The STICH trial unravelled. Eur J Heart Fail. 2010;12: 1024-7.

8. Conte J. An indictment of the STICH trial: "True, true, and unrelated" J Heart Lung Transplant. 2010;29:491-6.

9. Athanasuleas C, Buckberg G, Conte J. The STICH trial data: keep it simple. J Thorac Cardiovasc Surg. 2015;149:1682-3.

10. Mack MJ. Coronary artery disease: how should the STICH trial results affect clinical practice? Nat Rev Cardiol. 2011;8:427-8.

11. Fang JC. Underestimating medical therapy for coronary disease... again. $N$ Engl J Med. 2011;364:1671-3.

12. Bonow RO, Maurer G, Lee KL, Holly TA, Binkley PF, Desvigne-Nickens P. Myocardial viability and survival in ischemic left ventricular dysfunction. $N$ Engl J Med. 2011;364:1617-25.

13. Jolicœur EM, Dunning A, Castelvecchio S, Dabrowski R, Waclawiw MA, Petrie MC, et al. Importance of angina in patients with coronary disease, heart failure, and left ventricular systolic dysfunction: insights from STICH. J Am Coll Cardiol. 2015;66:2092-100.

14. Panza JA, Velazquez EJ, She L, Smith PK, Nicolau JC, Favaloro RR, et al. Extent of coronary and myocardial disease and benefit from surgical revascularization in ischemic LV dysfunction. J Am Coll Cardiol. 2014;64:553-61. Erratum in: J Am Coll Cardiol. 2014;64:1539.

15. Oh JK, Velazquez EJ, Menicanti L, Pohost GM, Bonow RO, Lin G, et al. Influence of baseline left ventricular function on the clinical outcome of surgical ventricular reconstruction in patients with ischaemic cardiomyopathy. Eur Heart J. 2013;34:39-47.

16. Michler RE, Rouleau JL, Al-Khalidi HR, Bonow RO, Pellikka PA, Pohost GM, et al. Insights from the STICH trial: change in left ventricular size after coronary artery bypass grafting with and without surgical ventricular reconstruction. J Thorac Cardiovasc Surg. 2013;146: 1139-45.e6.

17. Anavekar NS, Chareonthaitawee P, Narula J, Gersh BJ. Revascularization in patients with severe left ventricular dysfunction: is the assessment of viability still viable? J Am Coll Cardiol. 2016;67:2874-87.

18. Petrie MC, Jhund PS, She L, Adlbrecht C, Doenst T, Panza JA, et al. Ten-year outcomes after coronary artery bypass grafting according to age in patients with heart failure and left ventricular systolic dysfunction: an analysis of the extended follow-up of the STICH trial (Surgical Treatment for Ischemic Heart Failure). Circulation. 2016; 134:1314-24. 